Kumawula, Vol. 4, No.1, April 2021, Hal 137 - 144

DOI: https://doi.org/10.24198/kumawula.v4i1.32528

ISSN 2620-844X (online)

Tersedia online di http://jurnal.unpad.ac.id/kumawula/index

\title{
EDUKASI DARING TENTANG PENCEGAHAN COVID-19 PADA TOKOH MASYARAKAT DESA HAURPANGGUNG KABUPATEN GARUT
}

\author{
Udin Rosidin ${ }^{1}$, Umar Sumarna ${ }^{2}$, Theresia Eriyani ${ }^{3}$, Rohmahalia M Noor ${ }^{4}$ \\ ${ }^{1}$ Fakultas Keperawatan, Universitas Padjadjaran \\ ${ }^{2}$ Fakultas Keperawatan, Universitas Padjadjaran \\ ${ }^{3}$ Fakultas Keperawatan, Universitas Padjadjaran \\ ${ }^{4}$ Puskesmas Haurpanggung Garut
}

*Korespondensi : udin.rosidin@unpad.ac.id

\begin{abstract}
Currently, all countries are preoccupied with the Covid-19 pandemic. The data at the end of 2020 shows that cases have continued to increase worldwide. Likewise in Indonesia, cases continue to rise and most are in West Java. Haurpanggung, one of the villages in Garut District, has a high potential for Covid-19 transmission. The survey results show that most people in its society ignored health protocols. Furthermore, there are three public areas, such as markets, terminals and sports facilities that are possible sources of Covid-19 transmission. The purpose of this activity is to increase the knowledge, perceptions, attitudes and behavior of community leaders in preventing Covid-19 in Haurpanggung Village. The activity method is quantitative analytic and uses one group pretest and posttest without a comparison group. The statistical test used is the dependent t test (paired t test). The population is community leaders as partners for real work college students of Padjadjaran University, amounting to 40 people. The results of the activity showed that before online education was carried out, the lowest knowledge value was 6 points and after education it increased to 9.9 points. The perception value increased from 25 points to 33 . Attitude increased from 25 to 36 and behavior increased from 21 to 27 points. This result is a strategic potential for the prevention of Covid-19. The conclusion is that online education about the prevention of Covid-19 has an effect on increasing knowledge, perceptions, attitudes and behavior of community leaders in Haurpanggung Village.
\end{abstract}

Keywords: Online Education, Covid-19 Prevention, Community Figures

\begin{abstract}
ABSTRAK
Saat ini seluruh negara disibukkan dengan masalah kesehatan masyarakat yaitu pandemi Covid-19. Data akhir tahun 2020 melaporkan bahwa kasus terus meningkat di seluruh dunia. Demikian juga di Indonesia di mana kasus terus naik dan Jawa Barat termasuk provinsi dengan kasus terbanyak. Haurpanggung salah satu desa di Kabupaten Garut merupakan daerah yang memiliki potensi tinggi penularan Covid-19. Hasil survei menunjukkan masih banyak masyarakat Haurpanggung yang mengabaikan protokol kesehatan. Selain itu, terdapat tiga area publik seperti pasar, terminal, dan sarana olahraga yang memungkinkan menjadi sumber penularan Covid-19. Tujuan kegiatan ini adalah untuk meningkatkan pengetahuan, persepsi, sikap, dan perilaku tokoh masyarakat dalam pencegahan Covid-19 di Desa Haurpanggung. Metode kegiatan adalah analitik kuantitatif dengan jenis metode menggunakan one group pretest and postest tanpa kelompok pembanding. Uji statistik yang digunakan yaitu uji t dependen (paired t test). Populasinya adalah tokoh masyarakat sebagai mitra kuliah kerja nyata mahasiswa Universitas Padjadjaran yang berjumlah 40 orang. Hasil kegiatan menunjukan, sebelum dilakukan edukasi secara daring, nilai pengetahuan terendah sebesar 6 poin dan setelah dilakukan edukasi meningkat menjadi 9,9 poin. Nilai persepsi dari 25 poin meningkat menjadi 33 poin. Sikap meningkat dari 25 menjadi 36 dan perilaku meningkat dari 21 menjadi 27 poin. Hasil tersebut merupakan potensi yang strategis untuk pencegahan Covid-19. Kesimpulan yang dapat diambil adalah terdapat pengaruh edukasi daring tentang pencegahan Covid-19 terhadap peningkatan pengetahuan, persepsi, sikap, dan perilaku tokoh masyarakat di Desa Haurpanggung.
\end{abstract}

Kata Kunci : Edukasi Daring, Pencegahan Covid-19, Tokoh Masyarakat 


\section{PENDAHULUAN}

Pada era dengan kemajuan teknologi saat ini menunjukkan adanya keberhasilan pembangunan diberbagai bidang termasuk kesehatan. Bersamaan dengan keberhasilan pembangunan tersebut muncul masalah kesehatan yang melanda seluruh dunia. Padahal sesungguhnya pembangunan kesehatan dilaksanakan dengan tujuan untuk meningkatkan kesadaran, kemauan, dan kemampuan hidup sehat bagi setiap orang agar terwujud derajat kesehatan masyarakat yang setinggi tingginya. Masalah kesehatan yang terjadi adalah munculnya berbagai penyakit infeksi dan penyakit non-infeksi. Salah satu upaya untuk mencegah terserangnya penyakit tersebut adalah dengan melaksanakan perilaku hidup bersih dan sehat.

Perilaku hidup bersih dan sehat didefinisikan sebagai perilaku proaktif untuk memelihara dan meningkatkan kesehatan, mencegah risiko terjadinya penyakit, melindungi diri dari ancaman penyakit, serta berperan aktif dalam gerakan kesehatan masyarakat. Upaya tersebut dilakukan untuk memberdayakan masyarakat dalam memelihara, meningkatkan dan melindungi kesehatannya. Sehingga masyarakat sadar, mau, dan mampu secara mandiri ikut aktif dalam meningkatkan status kesehatannya. Gerakan hidup sehat merupakan upaya yang sangat tepat dilakukan, terutama pada kondisi saat ini dimana seluruh negara sedang mengatasi masalah kesehatan dunia yaitu Pandemi Covid19.

Pencegahan Covid-19 harus dilakukan oleh seluruh warga masyarakat. Maka kewaspadaan kesehatan masyarakat harus diterapkan. Masyarakat harus disiplin melaksanakan upaya-upaya promotif dan preventif dalam pencegahan Covid-19. Masyarakat yang berisiko terinfeksi adalah mereka yang kontak erat dengan pasien Covid19 atau yang merawat pasien Covid-19. Selain itu, masyarakat yang rentan terkena adalah mereka yang berada pada kelompok bayi dan balita, lansia, orang dengan imun yang rendah serta orang yang memiliki penyakit bawaan seperti TBC, diabetes, gangguan ginjal, jantung dan asma. Tindakan pencegahan merupakan kunci penerapan di masyarakat.(Larasati \& Haribowo, 2020).

Upaya pencegahan merupakan sebuah perilaku kesehatan yang harus dilaksanakan oleh seluruh masyarakat. Perilaku kesehatan menurut Green yang diambil dari (Soekidjo Notoatmodjo, 2012) terbentuk dari tiga faktor, yaitu;

1) Predisposing factors yang terwujud dalam pengetahuan, persepsi, sikap, kepercayaan, keyakinan dan nilai nilai,

2) Enabling factors yang terwujud dalam lingkungan fisik dan sarana (fasilitas) kesehatan dan,

3) Reinforcing factors yang terwujud dalam sikap, dan perilaku petugas kesehatan.

Berdasarkan teori tersebut, perilaku kesehatan akan dilaksanakan oleh setiap orang apabila memiliki pengetahuan, persepsi, sikap, dan nilai-nilai yang dianut mendukung terhadap pelaksanaan perilaku tersebut. Selain itu, didukung oleh ketersediaan sarana dan fasilitas yang cukup serta sikap, dan perilaku petugas dan tokoh masyarakat yang mendukung pelaksanaan pencegahan Covid19.

Pencegahan Covid-19 terus dilakukan oleh pemerintah pusat maupun daerah agar bisa memutus rantai penularannya. Protokol kesehatan untuk pencegahan Covid-19 terus disosialisakan kepada masyarakat. Namun, belum semua warga masyarakat bisa berdisiplin melaksanakan pencegahan Covid19. Akibatnya kasus tersebut terus meningkat baik di berbagai negara luar maupun di Indonesia. Provinsi Jawa Barat juga merupakan salah satu dari tiga provinsi yang memiliki kasus Covid-19 terbanyak di Indonesia sedangkan Kabupaten Garut termasuk ke dalam lima besar yang memiliki kasus Covid-19 terbanyak di Jawa Barat. (Pusat Informasi dan Koordinasi Covid-19 Provinsi Jawabarat, 2021). Desa Haurpanggung adalah salah satu desa di 
Kabuapten Garut yang memiliki risiko tinggi penularan Covid-19.

Dalam survei awal yang dilaksanakan oleh tim PPM di Desa Haurpanggung mendapatkan data masih banyak masyarakat yang mengabaikan protokol kesehatan. Apalagi Di Desa Haurpanggung terdapat tiga area publik seperti pasar, terminal dan sarana olahraga yang memungkinkan menjadi tepat berisiko terjadinya kerumunan banyak orang. Hasil wawancara dengan beberapa anggota masyarakat menunjukkan masih ada yang memiliki persepsi yang salah tentang Covid19. Mereka beranggapan bahwa Covid-19 adalah hal yang tidak nyata, sehingga mengabaikan protokol kesehatan. Selain itu di daerah terminal dan pasar masih banyak yang tidak pakai masker dan tidak jaga jarak. Apabila keadaan tersebut dibiarkan maka insiden orang terpapar dengan Covid-19 akan terus meningkat. Untuk mencegah hal tersebut perlu dilakukan upaya peningkatan pengetahuan, persepsi, sikap, dan perilaku masyarakat dalam memutus rantai penularan Covid-19. Upaya tersebut bisa dilakukan melalui peran tokoh masyarakat dalam perilaku pencegahan Covid-19.

Menurut penelitian yang membahas tentang faktor-faktor yang berhubungan dengan Pelaksanaan PHBS Rumah Tangga di Desa Jayaraga Kabupaten Garut menunjukkan bahwa peran tokoh masyarakat merupakan faktor yang sangat dominan dalam pelaksanaan perilaku hidup bersih dan sehat (Rosidin 2019). Karena pencegahan Covid-19 memerlukan perilaku hidup sehat maka peran tokoh masyarakat dalam upaya pencegahan Covid-19 merupakan hal yang sangat penting untuk dilakukan. Peran tokoh masyarakat tersebut merupakan dukungan sosial yang sangat baik untuk pencegahan Covid-19. Tokoh masyarakat adalah panutan dan pemimpin baik formal maupun non-formal yang ada di masyarakat. Setiap perkataan dan perilaku tokoh masyarakat akan menjadi contoh dan akan diikuti oleh setiap anggota masyarakat. Pelaksanaan pencegahan Covid19 sangat memerlukan dukungan tokoh masyarakat. Melalui dukungan tersebut diharapkan dapat meningkatkan potensi masyarakat untuk mencegah penularan Covid19. (Rosidin, Rahayuwati, \& Herawati, 2020)

Dukungan tokoh masyarakat pada dasarnya adalah menyosialisasikan program kesehatan, agar masyarakat mau menerima dan mau berpartisipasi. Kesinambungan program kesehatan akan terhambat apabila dukungan tokoh masyarakat hanya sebatas mensosialisakan program. Dukungan tokoh masyarakat saat ini masih terbatas pada fase sekadar terlibat dan menjadi bagian dari kegiatan. Upaya pencegahan Covid-19 tidak cukup hanya sekedar memberikan informasi kepada masyarakat. Upaya pencegahan tersebut perlu dukungan dan peran aktif dari para tokoh masyarakat. Tokoh masyarakat seperti kader kesehatan merupakan unsur masyarakat yang memiliki peranan penting dalam pencegahan Covid-19. Apalagi pada saat ini dimana Covid19 sudah merupakan bagian dari masalah kesehatan yang ada. Karena kita akan selalu berdampingan dengan Covid-19 maka salah satu cara untuk tidak terpapar adalah dengan cara hidup sehat. Tokoh masyarakat harus selalu memberikan informasi yang benar kepada masyarakat juga memberi contoh yang baik supaya tidak terpapar Covid-19. Oleh karena itu, tokoh masyarakat harus memiliki pengetahuan, persepsi, sikap, dan perilaku yang benar tentang pencegahan Covid-19.

Berdasarkan permasalahan tersebut, dalam rangka meningkatkan pengetahuan, persepsi, sikap, dan perilaku tokoh masyarakat tentang pencegahan Covid-19, tim pengabdian melakukan kegiatan edukasi daring tentang pencegahan Covid-19 kepada tokoh masyarakat di Desa Haurpanggung Kecamatan Tarogong Kidul Kabupaten Garut.

\section{METODE}

Metode kegiatan yang digunakan yaitu analitik kuantitatif, jenis metode dengan 
menggunakan one group pretest and postest tanpa kelompok pembanding. Variabel dalam kegiatan ini yaitu pengetahuan, persepsi, sikap, dan perilaku tokoh masyarakat dalam pencegahan Covid-19. Pengumpulan data dilakukan secara daring. Sumber data adalah tokoh masyarakat yang bersedia menjadi responden. Jumlah responden sebanyak 40 orang yang diambil secara acak. Instrumen menggunakan skala likert dengan empat alternatif jawaban. Skor yang diberikan antara 1 sampai dengan 4. Data yang terkumpul dianalisis sehingga mendapatkan data mean, nilai minimum dan maksimum, standar deviasi sebelum dan sesudah dilaksanakan edukasi daring serta nilai $p$ value. Analisa data menggunakan analisa univariat dan bivariat. Uji statistik yang digunakan yaitu uji t dependen (uji paired $t$ test).

\section{HASIL DAN PEMBAHASAN}

Tokoh masyarakat sebagai mitra pengabdian kepada masyarakat (PPM) seluruhnya adalah kader kesehatan. Karakteristik kader kesehatan terdiri dari pendidikan, umur dan lama menjadi kader. Data disajikan dalam bentuk distribusi frekuensi. Karakteristik tokoh masyarakat disajikan pada tabel 1. berikut ini :

Tabel 1. Distribusi Frekuensi arakteristik

Tokoh Masyakat mitra PPM di Desa Haurpanggung $(\mathrm{N}=40)$

\begin{tabular}{lcc}
\hline Karakteristik & Frekuensi & Persentase \\
\hline Pendidikan & \multicolumn{2}{c}{12.5} \\
SD & 5 & 10 \\
SMP & 4 & \\
\hline
\end{tabular}

\begin{tabular}{lcc}
\hline SMA & 24 & 60 \\
Sarjana & 6 & 15 \\
Pasca Sarjana & 1 & 2,5 \\
\hline
\end{tabular}

\begin{tabular}{lcc}
\hline Umur & & \\
$20-29$ & 7 & 17,5 \\
$30-39$ & 11 & 27,5 \\
$40-50$ & 16 & 40 \\
$>50$ & 6 & 15 \\
\hline Menjadi Kader & & \\
$<4$ tahun & 15 & 37,5 \\
$4-7$ tahun & 10 & 25 \\
$8-12$ tahun & 6 & 15 \\
$>12$ tahun & 9 & 22,5
\end{tabular}

Berdasarkan tabel 1, karakteristik tokoh masyarakat sebagai mitra kegiatan PPM menunjukkan lebih dari setengahnya memiliki tingkat pendidikan SMA yaitu sebanyak $60 \%$ dan sebagian kecil pendidikannya pasca sarjana yaitu sebanyak 2,5\%. Karakteristik umur hampir setengahnya berada pada rentang usia 40-50 tahun dengan persentase $40 \%$. Sedangkan lama menjadi kader hampir setengahnya dibawah 4 tahun dengan persentase $37,5 \%$. Hasil kegiatan pengabdian menujukkan adanya peningkatan pengetahuan, persepsi, sikap, dan perilaku tokoh masyarakat dalam pencegahan Covid-19 di Desa Haurpanggung. Hasil analisis tersebut disajikan dalam tabel 2 berikut :

Tabel 2. Peningkatan Pengetahuan, Persepsi, Sikap, dan perilaku Tokoh Masyarakat tentang Pencegahan Covid-19 di Desa Haurpanggung Garut (N:40)

\begin{tabular}{lrrccc}
\hline Kategori & Mean & SD & Min & Mak & P Value \\
\hline $\begin{array}{l}\text { Pengetahuan } \\
\text { - Pre-test }\end{array}$ & 8,6 & 1,16 & 6 & 10 & \\
- Post-test & 9,9 & 0,26 & 9 & 10 & 0,000 \\
\hline
\end{tabular}




\begin{tabular}{lccccc}
\hline Persepsi & & & & & \\
- Pre-test & 32,5 & 3,07 & 25 & 38 & 0,000 \\
- Post-test & 37 & 1,79 & 33 & 40 & \\
\hline Sikap & & & & & \\
- Pre-test & 33,5 & 3,48 & 25 & 40 & 0,000 \\
- Post-test & 38,1 & 1,78 & 36 & 40 & \\
\hline Perilaku & & & & & \\
- Pre-test & 32,8 & 4,24 & 21 & 40 & 0,000 \\
- Pos-ttest & 38,1 & 2,16 & 27 & 40 & \\
\hline
\end{tabular}

Berdasarkan tabel 2 menunjukan bahwa rata-rata nilai pengetahuan, persepsi, sikap, dan perilaku tokoh masyarakat tentang pencegahan Covid-19 meningkat setelah dilakukan edukasi secara daring. Sebelum dilakukan edukasi, nilai pengetahuan terendah sebesar 6 dan setelah dilakukan edukasi meningkat menjadi 9,9 poin. Demikian juga dengan nilai persepsi dari 25 meningkat menjadi 33 poin. Sikap meningkat dari 25 menjadi 36 poin dan perilaku menngkat dari 21 menjadi 27 poin. Peningkatan nilai pengetahuan sebesar 3,3 poin, peningkatan nilai persepsi sebesar 4,5 poin, peningkatan nilai sikap sebesar 4,6 poin dan peningkatan nilai perilaku sebesar 5,3 poin. Karena nilai $p$ value $0,00<$ 0,05 maka ada pengaruh kegiatan edukasi daring tentang pencegahan Covid-19 terhadap pengetahuan, persepsi, sikap, dan perilaku tokoh masyarakat di Desa Haurpanggung.

Berdasarkan uji statistik yang dilakukan menunjukkan ada pengaruh yang signifikan pelaksanaan edukasi secara daring tentang pencegahan Covid-19 pada tokoh masyarakat desa Haurpanggung terhadap peningkatan pengetahuan, persepsi, sikap, dan perilaku pencegahan Covid-19. Hal ini sesuai dengan penelitian yang dilakukan (Amanda, Rosidin, \& Permana, 2020) bahwa ada pengaruh pendidikan kesehatan yang dilaksanakan selama dua kali pertemuan dengan kader kesehatan kepada peningkatan pengetahuan dan keterampilan responden. Peningkatan pengetahuan, persepsi, sikap, dan perilaku tokoh masyarakat tentang pencegahan Covid-19 ini sangat dimungkinkan karena dalam kegiatan edukasi daring ini dilaksanakan secara personal selama dua sampai tiga kali pertemuan melalui kelompok kecil. Satu orang mahasiswa KKN membina dua orang tokoh masyarakat secara intensif. Pendidikan kesehatan yang dilaksanakan melalui metode pemecahan masalah dalam kelompok kecil sangat efektif untuk meningkatkan pengetahuan sikap dan ketrampilan seseorang (Hayati \& Romdhini, 2013). Pelaksanaan edukasi secara daring ini diikuti dengan sungguh sungguh oleh tokoh masyarakat di Desa Haurpanggung karena mahasiswa KKN mengemas media edukasi dengan baik dan mudah dimengerti seperti video, leaflet, dan poster. Materi dikemas menarik dalam bentuk video, poster dan leaflet yang dikirim melalui personal chat akan menjadi perhatian masyarakat untuk melihat atau membacanya (Rosidin, Witdiawati, \& Sumarna, 2020).

Dalam upaya menyamakan standar kegiatan edukasi yang dilakukan oleh mahasiswa KKN, tim pengabdian melakukan kegiatan pembekalan materi yang diberikan oleh dosen pembimbing lapangan, Kepala Puskesmas Haurpanggung dan Kepala Desa Haurpanggung.

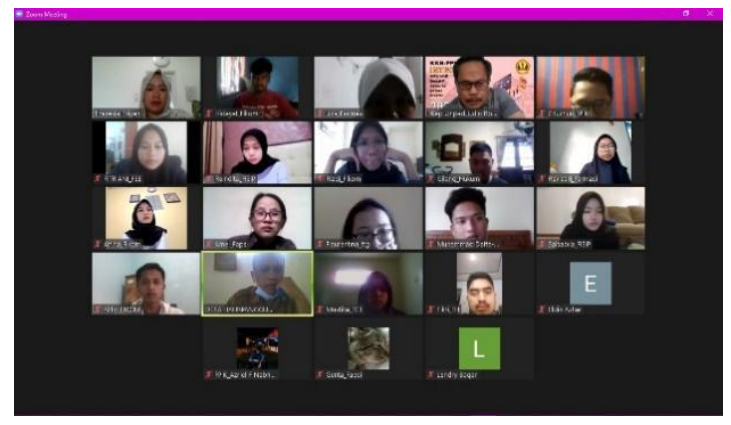




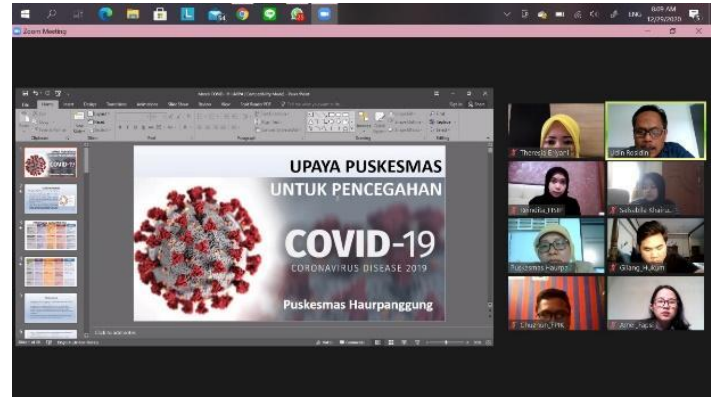

Gambar 1. Suasana Pembekalan Materi Edukasi oleh DPL, Kepala Puskesmas, dan Kepala Desa Haurpanggung

Dengan mempersiapkan mahasiswa peserta KKN secara baik maka hasil kegiatan pengabdian dapat meningkatkan pengetahuan, persepsi, sikap, dan perilaku tokoh masyarakat dalam pencegahan Covid-19 di Desa Haurpanggung.

Hasil kegiatan ini juga sesuai dengan penelitian yang dilakukan (Wahyuningsih \& Astarani, 2018), yang menyatakan bahwa pengetahuan dan sikap serta keterampilan kader kesehatan dapat ditingkatkan dengan melakukan pendidikan kesehatan. Peningkatan pengetahuan tokoh masyarakat tentang pencegahan Covid-19 di Desa Haurpanggung merupakan upaya promotif yang sangat strategis dalam pencegahan Covid-19 karena tokoh masyarakat memiliki peran yang sangat besar dalam melaksanakan pencegahan Covid-19. Melalui peran tokoh masyarakat dalam pencegahan Covid-19 yang baik merupakan contoh perilaku yang akan dilaksanakan oleh seluruh masyarakat yang ada di lingkungannya (Rosidin, Rahayuwati, et al., 2020).

Tokoh masyarakat yang telah dijadikan mitra kegiatan PPM dalam edukasi daring tentang pencegahan Covid-19 di Desa Haurpanggung diharapkan dapat menjalankan perannya sesuai dengan tuntutan pada kedukukannya tersebut. Tokoh masyarakat mempunyai peranan yang sangat penting dalam melaksanakan pencegahan Covid-19, karena tokoh masyarakat adalah orang yang memiliki kekuasaan dan kemampuan memengaruhi orang atau kelompok lain sesuai dengan keinginan dirinya menurut Budiardjo dalam (Rosidin, Rahayuwati, et al., 2020).

Tokoh masyarakat yang dibina dalam kegiatan PPM ini adalah tokoh msyarakat yang sangat perhatian pada masalah kesehatan. Tokoh masyarakat tersebut adalah kader kesehatan. Pendidikan kesehatan yang diberikan kepada kader kesehatan merupakan media yang tepat dalam menyosialisasikan upaya pencegahan Covid-19. Masyarakat saat ini sangat memerlukan adanya informasi tentang pencegahan Covid-19. Orang terdekat dengan masyarakat adalah tokoh masyarakat. Pengetahuan, persesepsi, sikap, dan perilaku dari tokoh masyarakat sangat diperlukan dalam menyosialisasikan pencegahan Covid-19 kepada masyarakat. Pengetahuan, persepsi, sikap, dan perilaku tokoh masyarakat perlu ditingkatkan agar dapat memberikan informasi dengan percaya diri tinggi dan menjadi contoh yang baik kepada masyarakat sesuai dengan protokol kesehatan tentang pencegahan Covid19.

Upaya peningkatan pengetahuan, persepsi, sikap, dan perilaku tokoh masyarakat dalam pencegahan Covid-19 harus terus ditingkatkan. Berbagai instansi yang ada memiliki kewajiban untuk terus memotivasi dan membimbing masyarakat melalui para tokohnya agar selalu menjalankan protokol kesehatan. Para tokoh masyarakat diharapkan untuk selalu memberikan informasi kepada masyarakat tentang pencegahan Covid-19. Penyebaran informasi yang tepat dapat meningkatkan pengetahuan seseorang (Sumarni, Rosidin, \& Sumarna, 2020). Hal tersebut sangat mungkin untuk dilaksanakan karena tokoh masyarakat di Desa Haurpanggung sangat aktif dan memiliki karakteristik yang mendukung terhadap pencegahan Covid-19. Karakteristik tokoh masyarakat yang jadi mitra kegiatan menjadi potensi yang sangat penting dalam upaya pencegahan Covid-19. Rata-rata usia mitra PPM lebih dari setengahnya berada pada kelompok usia produktif yaitu usia 30 -39 dan 40 -50 tahun. Pendidikan mereka juga sangat baik karena lebih dari setengahnya lulus 
SMA. Demikian juga sebagian besar dari mereka telah menjadi kader kesehatan selama lebih dari empat tahun. Kondisi tersebut merupakan potensi tokoh masyarakat di Desa Haurpanggung untuk selalu dikembangkan. Karakteristik sangat memengaruhi pada peningkatan pengetahuan dan kemampuan kader kesehatan. Peningkatan pengetahuan dan kemampuan kader kesehatan sangat ditentukan oleh karakteristik yang dimilikinya seperti umur, pendidikan, pekerjaan dan lamanya menjadi kader kesehatan (Rosidin, Sumarni, \& Suhendar, 2019).

Berbagai upaya untuk memutus mata rantai penularan Covid-19 tetap terus dilaksanakan oleh seluruh masyarakat. Melalui tokoh masyarakat diharapkan warga masyarakat dapat melaksanakan protokol kesehatan tanpa paksaan. Untuk hal tersebut sangat diperlukan adanya pemahaman yang benar tentang pencegahan Covid-19. Sehingga masyarakat melaksanakan perilaku kesehatan atas dasar pemahamannya. Perilaku kesehatan menurut (Notoatmodjo 2012) adalah respon seseorang terhadap stimulus atau objek yang berkaitan dengan sehat sakit, penyakit dan faktor-faktor yang memengaruhi sehat sakit (kesehatan) seperti lingkungan, makanan, minuman, dan pelayanan kesehatan. Definisi lain perilaku kesehatan adalah semua aktivitas atau kegiatan seseorang baik yang dapat diamati maupun yang tidak dapat diamati yang berkaitan dengan pemeliharaan dan peningkatan kesehatan. Agar masyarakat dapat melaksanakan perilaku sehat tanpa paksaan maka harus diperhatikan ranah perilaku yang terdiri dari : Pengetahuan (knowledge), sikap (attitude) dan tindakan atau praktik (practice). Melalui ranah tersebut maka perilaku kesehatan dapat dilaksanakan (Notoatmodjo 2012).

Materi edukasi daring yang diberikan disesuaikan dengan Pedoman Pencegahan dan Pengendalian Covid-19 yang dikeluarkan oleh Kementerian Kesehatan Republik Indonesia. Langkah-langkah pencegahan tersebut dikemas dalam media poster, leaflet, dan video simulasi perilaku pencegahan Covid-19. Pesan-pesan edukasi yang diberikan meliputi: 1) Melakukan kebersihan tangan menggunakan hand sanitizer jika tangan tidak terlihat kotor atau cuci tangan dengan sabun jika tangan terlihat kotor; 2) Menghindari menyentuh mata, hidung dan mulut; 3) Terapkan etika batuk atau bersin dengan menutup hidung dan mulut dengan lengan atas bagian dalam atau tisu, lalu buanglah tisu ke tempat sampah; 4) Pakailah masker medis jika memiliki gejala pernapasan dan melakukan kebersihan tangan setelah membuang masker; 5) Menjaga jarak (minimal 1 meter) dari orang yang mengalami gejala gangguan pernapasan (Kemenkes, 2020)

Media edukasi yang beisi pesan pencegahan Covid-19 tersebut disampaikan kepada tokoh masyarakat dengan bahasa yang mudah dipahami dan mudah dilaksanakan. Sehingga para tokoh masyarakat sebagai mitra PPM dapat mengikti kegiatan dengan baik dan penuh perhatian sampai selesai. Setelah selesai mengikuti kegiatan ini para tokoh masyarakat mitra PPM akan menindaklanjuti kegiatan dengan melakukan edukasi tentang pencegahan Covid-19 kepada dua orang warga sekitarnya. Media poster, leaflet, dan video tentang pencegahan Covid-19 yang diberikan menjadi media pendidikan kesehatan yang akan dipakai para tokoh masyarakat dalam menyosialisasikan perilaku pencegahan Covid19 kepada masyarakat sekitarnya. Media edukasi seperti poster, leaflet, dan video merupakan media yang efektif dalam melaksanakanan edukasi secara daring (Aba, Nirmala, Saputri, \& Hasyim, 2020).

\section{SIMPULAN}

Hasil kegiatan pengabdian ini menunjukkan adanya pengaruh pelaksanaan edukasi daring tentang pencegahan Covid-19 pada tokoh masyarakat di Desa Haurpanggung Garut. Peningkatan nilai pengetahuan sebesar 3,3 poin, peningkatan nilai persepsi sebesar 4,5 poin, peningkatan nilai sikap sebesar 4,6 poin dan peningkatan nilai perilaku sebesar 5,3 poin. Berdasarkan hasil tersebut diharapkan tokoh masyarakat yang menjadi mitra kegiatan PPM 
dapat menyosialisasikan materi yang diterimanya serta dapat memotivasi warga sekitarnya untuk melakukan pencegahan Covid-19 di Desa Haurpanggung Kabupaten Garut.

\section{UCAPAN TERIMA KASIH}

Kegiatan yang berjudul "Edukasi Daring tentang Pencegahan Covid-19 pada Tokoh Masyarakat di Desa Haurpanggung Kabupaten Garut" dapat berjalan dengan baik atas dukungan dari berbagai pihak baik secara morel maupun materil. Oleh karena itu, penulis ingin mengucapkan terimakasih yang sebesarbesarnya kepada: Rektor Universitas Padjadjaran, Direktur Riset dan Pengabdian Pada Masyarakat Unpad, Dekan Fakultas Keperawatan Unpad, Kepala Puskesmas Haurpanggung, Kepala Desa Haurpanggung, Para Tokoh Masyarakat Mitra KKN, Mahasiswa peserta KKN Semester Ganjil tahun akademik 2020/2021 dan seluruh pihak yang penulis tidak bisa sebutkan satu persatu. Akhir kata penulis ucapkan, semoga kebaikan yang dilakukan oleh pihak-pihak diatas dibalas oleh Allah SWT, Aamiin.

\section{DAFTAR PUSTAKA}

Aba, L., Nirmala, F., Saputri, A. I., \& Hasyim, M. S. (2020). Efektivitas Pemberian Edukasi secara Online melalui Media Video dan Leaflet terhadap Tingkat Pengetahuan Pencegahan Covid-19 di Kota Baubau. Jurnal Farmasi Galenika (Galenika Journal of Pharmacy)(eJournal), 6(2).

Amanda, S., Rosidin, U., \& Permana, R. H. (2020). Pengaruh Pendidikan Kesehatan Senam Diabetes Melitus terhadap Pengetahuan Kader Kesehatan. Media Karya Kesehatan, 3(2).

Hayati, L., \& Romdhini, M. U. (2013). Penerapan Pendekatan Pemecahan Masalah melalui Belajar dalam Kelompok Kecil untuk Meningkatkan Profesi Belajar pada Mata Kuliah Teori Peluang. Jurnal Teknodik, 159-168.
Kemenkes. (2020). Pedoman Pencegahan dan Pengendalian Covid-19.

Larasati, A. L., \& Haribowo, C. (2020). Penggunaan Desinfektan dan Antiseptik Pada Pencegahan Penularan Covid-19 di Masyarakat. Majalah Farmasetika, 5(3), 137-145.

Notoatmodjo, S. (n.d.). Promosi Kesehatan dan Perilaku Kesehatan. Jakarta: Rineka Cipta, 2012.

Notoatmodjo, S. (2012). Promosi Kesehatan Dan Ilmu Perilaku. Jakarta: PT Rineka Cipta.

Pusat Informasi dan Koordinasi Covid-19 Provinsi Jawabarat (2021)

Rosidin, U., Rahayuwati, L., \& Herawati, E. (2020). Perilaku dan Peran Tokoh Masyarakat dalam Pencegahan dan Penanggulangan Pandemi Covid-19 di Desa Jayaraga, Kabupaten Garut. Umbara, 5(1), 42-50.

Rosidin, U., Sumarni, N., \& Suhendar, I. (2019). Penyuluhan tentang Aktifitas Fisik dalam Peningkatan Status Kesehatan. Media Karya Kesehatan, 2(2).

Rosidin, U., Witdiawati, W., \& Sumarna, U. (2020). Beraksi Cegah Penyakit Tidak Menular Di RW 2 Kelurahan Jayawaras Tarogong Kidul Garut. Kumawula: Jurnal Pengabdian Kepada Masyarakat, 3(3), 507-514.

Rosidin Udin, Sumarna Umar, E. T. (2019). Determinan Pelaksanaan PHBS Rumah Tangga di Desa Jayaraga Tarogong Kidul Kabupaten Garut. Jurnal Keperawatan BSI, 7(1).

Sumarni, N., Rosidin, U., \& Sumarna, U. (2020). Penyuluhan Kesehatan Tentang Jajanan Sehat di Sekolah Dasar Negeri Jati III Tarogong Kaler Garut. Kumawula: Jurnal Pengabdian Kepada Masyarakat, 3(2), 289-297.

Wahyuningsih, A., \& Astarani, K. (2018). Pendidikan Kesehatan Meningkatkan Pengetahuan, Sikap dan Ketrampilan Kader Dalam Tatalaksana Anak Sakit ISPA. Jurnal Penelitian Keperawatan, 4(1). 